Conclusions Blood lactate, base excess, leukocyte count and percentage of bastonades are suitable markers of mortality. Blood glucose, central venous oxygen saturation and cardiac troponin-I are valued predictors of sepsis, and the last two were also reliable markers of MODS and CPR marker only the latter.

\section{MORTALITY IN POST-CARDIAC SURGERY IN CHILDREN: THE ROLE OF MULTIPLE ORGAN DYSFUNCTION}

doi:10.1136/archdischild-2012-302724.1657

${ }^{1} \mathrm{~T}$ da Rocha, ${ }^{2} \mathrm{~A}$ Botta, ${ }^{2} \mathrm{C}$ Ricachinevsky, ${ }^{2} \mathrm{LD}$ Mulle, 'P Carvalho. 'Uti Pediatrica Hospital Santo Antonio, Universidade Federal do Rio Grande do Sul; '2Uti Pediatrica Hospital Santo Antonio, Santa Casa de Misericórdia de Porto Alegre, Porto Alegre, Brazil

Background and Aim The multiple organ dyfunction syndrome (MODS) is associated to worse prognosis in critical setting. Its role after open heart surgery is still purely studied.

Methods We made a retrospective cohort of 121children to study factors associated to mortality after open heart surgery such as systemic inflammatory response syndrome (SIRS), MODS, sepsis, low cardiac output syndrome (LCOS), respiratory and cardiac support time.

Results $7.4 \%$ of non survivors occurred. The presence of sepsis in the first postoperative day had the highest odds ratio $(\mathrm{OR})=$ 31.71 (2.6 to 393.8), followed by renal dysfunction on the third day, $\mathrm{OD}=14.12 .9$ to 66.6); uni ventricular correction, $\mathrm{OD}=14.2$ (2.9 to 66.66); the presence of MODS on the third day, $O D=10.0$ (1.9 to 50 9); presence of LCOS on the fifth day, $O D=9.1$ (2.1 to 40.2); and cardiac and respiratory dysfunction in the fifth day, $\mathrm{OD}=6$ (1.4 to 25.6). On the other hand, the absence of SIRS in the immediate postoperative period was protective, with $\mathrm{OD}=0.92$ (0.87 to 0.97 ). Furthermore, the mean time of cardiac support was higher in non survivors ( 98.8 vs. 53.7 hours), also respiratory support ( $42.2 \mathrm{~h}$ vs. 87 hours) and time of hypotension ( $85.2 \mathrm{~h}$ vs. 62.2 hours) than in survivors $(\mathrm{p}<0.05)$.

Conclusions The increased risk of mortality due to MODS appears to be caused by primary cardiac dysfunction, as there is also an association with LCOS, renal and respiratory dysfunctions secondary to the first.

\section{ACUTE KIDNEY INJURY AFTER HEART SURGERY IN CHILDREN}

doi:10.1136/archdischild-2012-302724.1658

${ }^{1,2}$ MGDS El Halal, 'PRA Carvalho, ${ }^{2} \mathrm{CV}$ Bohrer, ${ }^{2} \mathrm{AP}$ Pearson. ${ }^{1}$ Universidade Federal do Rio Grande do Sul; ${ }^{2 H o s p i t a l ~ d a ~ C r i a n c ̧ a ~ S a n t o ~ A n t o ̂ n i o, ~ P o r t o ~ A l e g r e, ~ B r a z i l ~}$

Background and Aims Acute kidney injury (AKI) has been associated to adverse outcomes in children after heart surgery, but previous studies have used several different definitions of AKI. After publication of the pediatric RIFLE (pRIFLE) criteria, it has been widely used as a definition for AKI in children. This study aims to investigate association between occurrence of AKI according to pRIFLE criteria and adverse outcomes in children after heart surgery.

Methods Children submitted to open heart surgery in a hospital in Brazil were followed from arrival until death or discharge from the Pediatric Intensive care Unit (PICU). The exposition variable was occurrence of AKI according to pRIFLE criteria, which divides AKI in three categories: R-Risk, I-Injury, F-Failure, according to changes in urine output or the estimated glomerular filtration rate. The outcomes studied were death, length of mechanical ventilation (MV) and length of PICU stay.

Results Eighty five children were studied. Forty seven (55.3\%) did not have AKI during PICU stay, while 22 (25.9\%), 7 (8.2\%) and $9(10.6 \%)$ were classified as R, I and F, respectively. Comparing to children who did not develop AKI, the relative risk for death was
1.07 (0.09-12.48), 16.87 (2.14-132.50) and 11.25 (1.55-81.61) in the $\mathrm{R}, \mathrm{I}$ and $\mathrm{F}$ group, respectively $(\mathrm{p}=0,001)$. Lengths of $\mathrm{MV}$ and of PICU stay were significantly higher in those with any degree of AKI.

Conclusions Occurrence of AKI according to pRIFLE criteria is associated to adverse outcomes in children after open heart surgery.

\section{POST - OPERATIVE ICU COURSE OF INFANT BELOW 2.2 KG UNDERGOING CARDIAC SURGERY}

doi:10.1136/archdischild-2012-302724.1659

A Mehmood, SR Ismail, MS Kabbani, RM Abusuliman, HK Najm. Cardiac SciencesPcicu, King Abdulaziz Medical City for National Guards - Pediatric Cardiac Intensive Care, Riyadh, Saudi Arabia

Introduction Infants with low body weight (LBW) are major challenges for post cardiac surgery care. We conducted this study to compare post-operative course and outcome of infant weighing $2.2 \mathrm{Kg}$ or less with matching group of infants with normal body weight who underwent similar cardiac surgery.

Methods We reviewed retrospectively all infants below $2.2 \mathrm{~kg}$ who underwent cardiac operation at our institution from January 2001 to March 2011. Cases with LBW (group A) were compared with matching group (Group B) of normal body weight infants who had similar cardiac surgery and matching surgical risk category. We compared demographic, ICU parameters, complications and short-term outcome of both groups.

Results Thirty seven patients were included in group A and 39 in group B. Except for Weight $(2.13 \pm 0.08 \mathrm{~kg}$ in Group A vs. $3.17 \pm 0.2 \mathrm{~kg}$ in group B); there was no statistical difference in demographic data between both groups. Cardiac procedures included coarctation repair, Arterial switch, VSD repair, tetralogy of Fallot repair, systemic to pulmonary shunt and Norwood procedures. Patients in group A had statistically significant difference from group $B$ in term of bypass time $(p=0.01)$, duration of inotrops $(p=0.01)$, duration of mechanical ventilation $(p=0.004)$, number of re-intubations $(p=0.015)$, PCICU length of stay $(p=0.007)$ and mortality $(13.5 \%$ in group $\mathrm{A}$ vs. $0 \%$ in group $\mathrm{B}, \mathrm{p}$ value 0.02 ).

Conclusion Patients with LBW below $2.2 \mathrm{Kg}$ can go for cardiac surgery with overall satisfactory result but with increase risk of ICU morbidity and mortality.

\section{RISK FACTORS FOR MORTALITY AFTER TRANSCATHETER INTERVENTION AFTER CARDIAC SURGERY IN CHILDREN WITH CONGENITAL HEART DISEASE}

doi:10.1136/archdischild-2012-302724.1660

${ }^{1} \mathrm{M}$ Amin, ${ }^{2} \mathrm{~A}$ Hussain, ${ }^{1} \mathrm{~A}$ Kouatli, ${ }^{1,3} \mathrm{~S}$ Deraz, ${ }^{4} \mathrm{H}$ Abozeid, ${ }^{4} \mathrm{~J}$ Al Ata. ${ }^{1} \mathrm{CVD}$, King Faisal Specialist Hospital \& Research Centre Gen. Org: ${ }^{2} \mathrm{CVD}$, King Faisal Specialist Hospital \& Research Centre, Jeddah, Saudi Arabia; ${ }^{3}$ Pediatrics, Minoufiya University, Shibin El Kom, Egypt; "King Faisal Specialist Hospital \& Research Centre Gen. Org, Jeddah, Saudi Arabia

Aim Risk stratification for mortality after cardiac catheterization in early post-operative children.

Introduction Transcatheter intervention has evolved overtime to expose high risk, sick chldren to such procedures. The risk of dying, rises significantly in emergent and critically sick patients. Rarely published, we reviewed records of 35 patients, 43 procedures during immediate/early post operative period after cardiac surgery for congenital heart disease.

Methods Multivariate analysis for age, weight, sex, time between surgery/intervention, and the intervention on natural vasculature/ synthetic material, was done, as possible risk factors for mortality. Results Thirty patients survived and cleared from ICU in due course. None of the risk factors could be attributed to the mortality. 